\title{
A Digital Diagnostic System for a Small Turbojet Engine
}

\author{
Rudolf Andoga ${ }^{*}$, Ladislav Főző ${ }^{* *}$, Ladislav Madarász ${ }^{* * *}$, \\ Tomáš Karol'
}

*Technical University of Košice, Faculty of Aeronautics, Department of Avionics, Rampová 7, 04121 Košice Slovakia, e-mail: rudolf.andoga@tuke.sk

Technical University of Košice, Faculty of Aeronautics, Department of Aviation
Engineering, Rampová 7, 04121 Košice Slovakia, e-mail: ladislav.fozo@ @uke.sk
${ }^{* * * *}$ Technical University of Košice, Faculty of Informatics and Electrical
Engineering, Department of Cybernetics and Artificial Intelligence, Letná 9,
04200 Košice Slovakia, e-mail: ladislav.madarasz @tuke.sk, tomas.karol@tuke.sk

Abstract: During the lifecycle of a system not only functionality but also other aspects like safety and reliability are very important. These terms are even more important when connected to aviation in engine and avionic systems control. The reason is simple, a failure must not cause a shutdown of a system during the flight as it would cause a catastrophe. The article deals with the proposal of a progressive diagnostics/backup system using a modified voting method with computational backup models using neural networks. The proposed architecture is expected to be suitable for turbojet engines and was tested on a laboratory object, a small turbojet engine MPM-20 with positive results under operational conditions.

\section{Introduction - Diagnostics in Aircraft Systems}

Progressive approaches in control and advances in the field of artificial intelligence have found their place in diagnostic systems. The application of such systems has shown the potential to increase the reliability and safety of the diagnosed system $[1,2,3]$. The problem of diagnostics is especially important in the field of aircraft avionic systems [1, 2, 3]. Modern aircraft are dependent on the errorless operation of different systems that are usually backed up and have built in diagnostics $[1,2,3,4,5]$. With the advent of digital systems, the field of diagnostics offers new possibilities in the implementation of progressive algorithms instead of traditional voting and bulky hardware back-up methods [2, 3 ]. Modern computers can run back-up controller and sensor models, thus creating 
highly redundant networks with greatly increased reliability $[5,6,7,8]$. Moreover, digital/electronic/electric devices and algorithms are more susceptible to errors, either due to interference or algorithmic overload problems; on the other hand miniaturization offers ways to overcome such problems [6,7]. The article will deal mainly with application of new approaches in diagnostics and back-up systems in the area of turbojet engines. As a test bed, a small turbojet engine MPM-20 that has been transformed into a digitally controlled system will be used. The engine is derived from TS-20/21 engines and is an ideal test bed for scientific purposes $[9,10,11,12]$.

\section{Intelligent Engine Control System with Diagnostics}

As the engine TS-21 has been adapted to full digital control $[9,10]$, the safety and diagnostics of critical parameters come into the forefront. The situational control system of the engine had to be expanded with diagnostic and back-up modules that detect faults in the digital control, sensors as well as the back-up systems to transfer the current engine control strategy into a back-up mode [2, 6, 7, 8]. The basic architecture of the designed system is shown in the figure 1 [12].

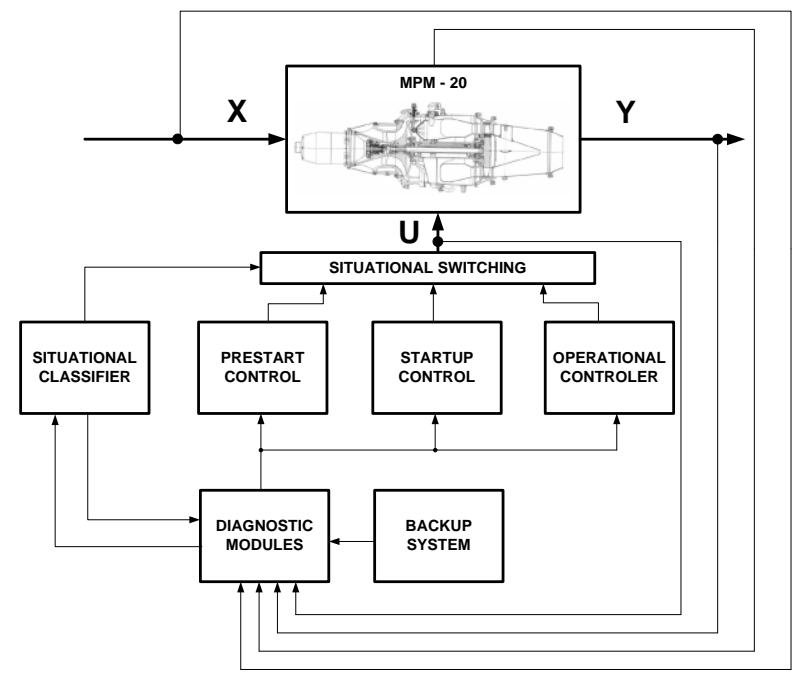

Figure 1

The situational control system with diagnostics and backup modules

The function of the system can be described as follows:

- The measured values (input, state, output and action) are deployed through the diagnostic module where model comparison will show if the measured parameters are erroneous. 
- In case of an error in any of the parameters, its value will be replaced by a value of the back-up sensor or an analytic back-up will be used (synthetic value calculated by a model).

- Further these values will enter the situational classifier that will select the actual state of the engine and the appropriate control algorithm.

The whole control process can be broken down into three basic situational frames which are [12]:

- pre-start diagnostics,

- $\quad$ start-up control,

- operational control and control with degraded control modes [2, 12].

Regarding software implementation, the whole situational control and diagnostic system is using Matlab/Simulink and LabView systems. Although both overlap in functionality, LabView is used mainly for data acquisition that is run with National Instruments data acquisition hardware, data visualization, simple calculations for certain situational frames (pre-start control, pre-start diagnostics) and is also used for running the back/up diagnostic module with voting method that will be described later. Matlab/Simulink is used for complex calculations and complex control algorithms and models. Simulink runs all neural networks and dynamic engine models used for diagnostics situational classifier and control, including servo-valve control and operational engine control.

\subsection{Pre-start diagnostics}

This situational frame is based on the pre-start control of aggregates that are necessary for start and operation of the engine. With its realization a diagnostic expert system has been chosen (Fig. 2) [12].

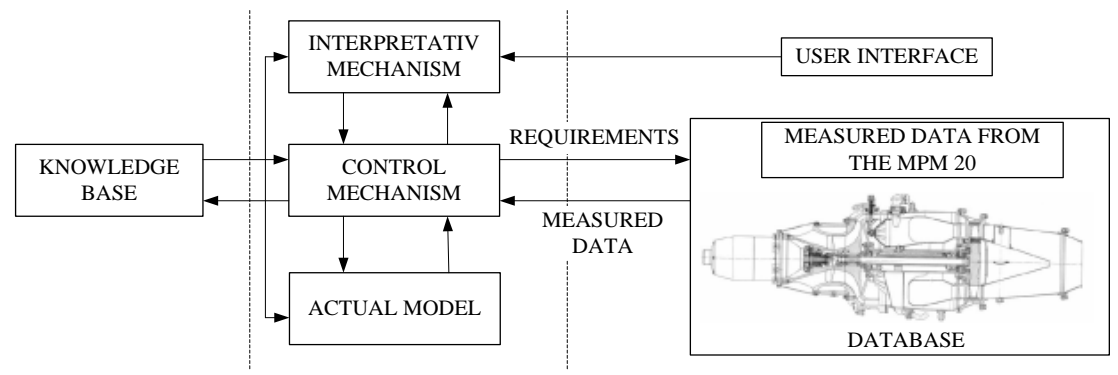

Figure 2

The scheme of the diagnostic expert system for MPM-20

The designed expert system is used to test all observed engine sensors tied to the engine parameters. The system using its knowledge base decides if all the parameters are at their usual levels and decides if the engine can be started. 
The whole process can be described as follows:

- Measured data are processed by the expert system and its knowledge base with rules in the form of inference network.

- The results of the process are shown to the user in the graphical interface.

The expert system has been implemented in LabView environment. Its knowledge base in the form of the inference network is shown in the Figure 3.

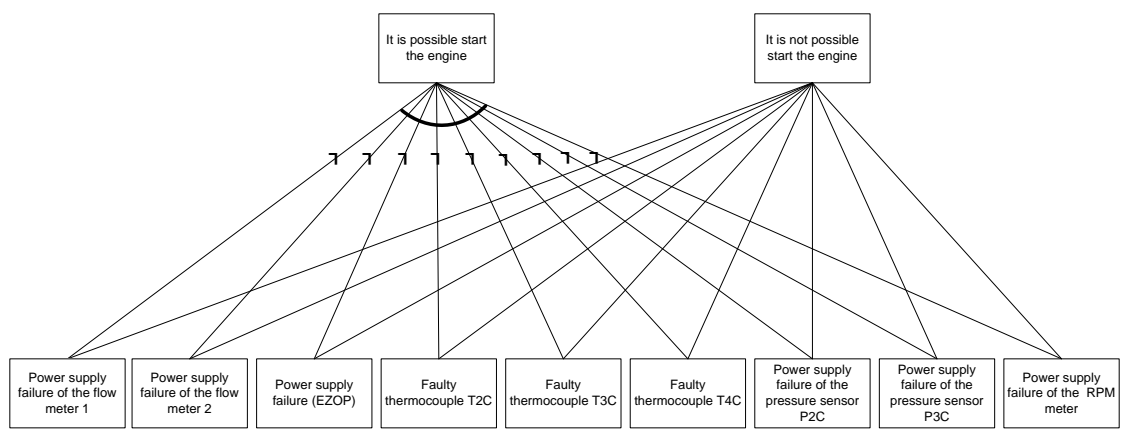

Figure 3

The inference network of the pre-start diagnostic expert system

\subsection{Pre-Start and Start-Up Control}

To implement the proposed algorithms, the hydro-mechanical fuel control unit has been replaced by the computer controlled servo valve LUN 6743. This represents the action element for control and it runs in Matlab and LabView environment as described in the beginning of the chapter 2. The flowchart is depicted in the Fig. 4.

Using a digitally-controlled actuator to meter fuel flow into the engine together with digitally-controlled auxiliary systems allows us to build a flexible control and diagnostic system utilizing the concept of a wireless sensor network in the future [14]. All elements can be controlled and turned on or off independently, tied only by algorithmic software links. This allows us to build a complex control system utilizing different control strategies according to situational control methodology. However, the utilization of complete digital control system puts higher demands on the functionality of all elements, because a failed sensor can cause catastrophic failure during digital engine startup that would not appear with hydromechanical control, where the lack of pressure will not allow any actuation. Now the system is dependent on values of speed, temperature and pressure that are presented in a digital form. The start-up of the engine is composed of two phases:

- Phase before ignition (control of auxiliary units - see Figure 4)

- Phase after ignition (situational frame startup - use of fuzzy situational controller) [9] 
A part of the start-up control is also formed by implementation of microsituational start-up fuzzy controller. This controller handles the engine and controls fuel flow according to the speed, temperature and temperature derivation using fuzzy inference system rule base, while also handling atypical situations during start-up after fuel ignition, such as excess temperatures, flameouts, stalls. The start-up controller is also tasked with decreasing the exhaust temperature peaks and securing smooth acceleration towards a normal idle operational state [9].

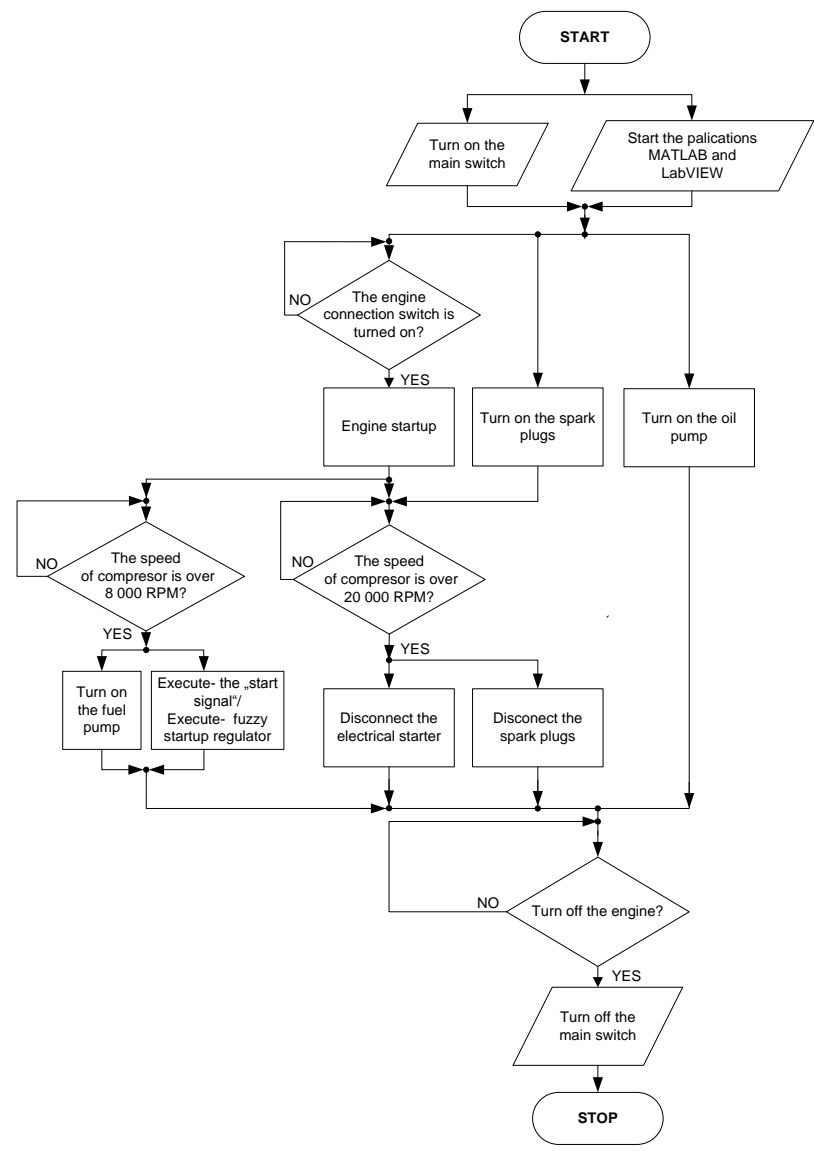

Figure 4

The inference network of the pre-start diagnostic expert system

\subsection{Operational Control}

During the operational control of the engine we use a double looped control circuit with inner loop controlling the fuel metering valve and the outer loop controlling the speed or other parameters of the engine using the methodology of situational 
control [11]. This means that the engine is controlled with different algorithms in different situational frames that are classified by the situational classifier. Normal operational is decomposed into different situational frames, such as stable operation, acceleration, deceleration, degraded modes, etc. [9]

\section{Diagnostic and Backup Module}

The core of the diagnostics and backup system is represented in the block of diagnostics/backup in Figure 1. The present control of the engine is done via fuel supply parameter and, as such, the engine represents a complex system with a single degree of freedom. The controlled parameter that defines the thrust of the engine is its speed. The speed of the engine determines the mass air flow through it, thus determining its thrust. As a testing parameter for the implementation of the presented diagnostic/backup approach, the parameter of speed has therefore been chosen. Contrary to other diagnostic systems, the presented system acts as a diagnostic but also backup system at the same time $[13,14,15]$. The primary way of obtaining of the engine's speed is the optical sensor [10, 11], while the other ways are synthetic model values of:

\section{- $\quad$ successive integration dynamic model,}

- a neural network.

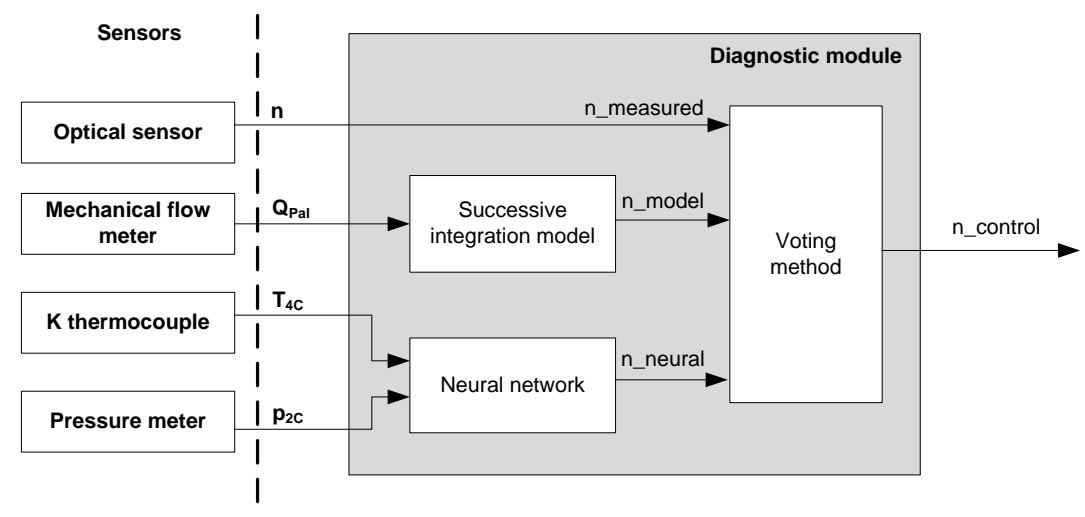

Figure 5

The structure of the diagnostic module

The structure of the diagnostic/backup module is shown in Figure 5. It shows that every input into the selection block has an independent sensor suite. This eliminates their mutual influence and increases reliability. The optical sensor can produce two types of erroneous outputs:

- A random value - caused by an electro-magnetic environmental conditions, 
- Sensor failure - caused by a loss of power, loss of communication channel, or loss of reflex area on the compressor blade.

The designed structural scheme for the realization of the diagnostic/backup module utilizing the concepts of majority methods is shown in the Figure 6.

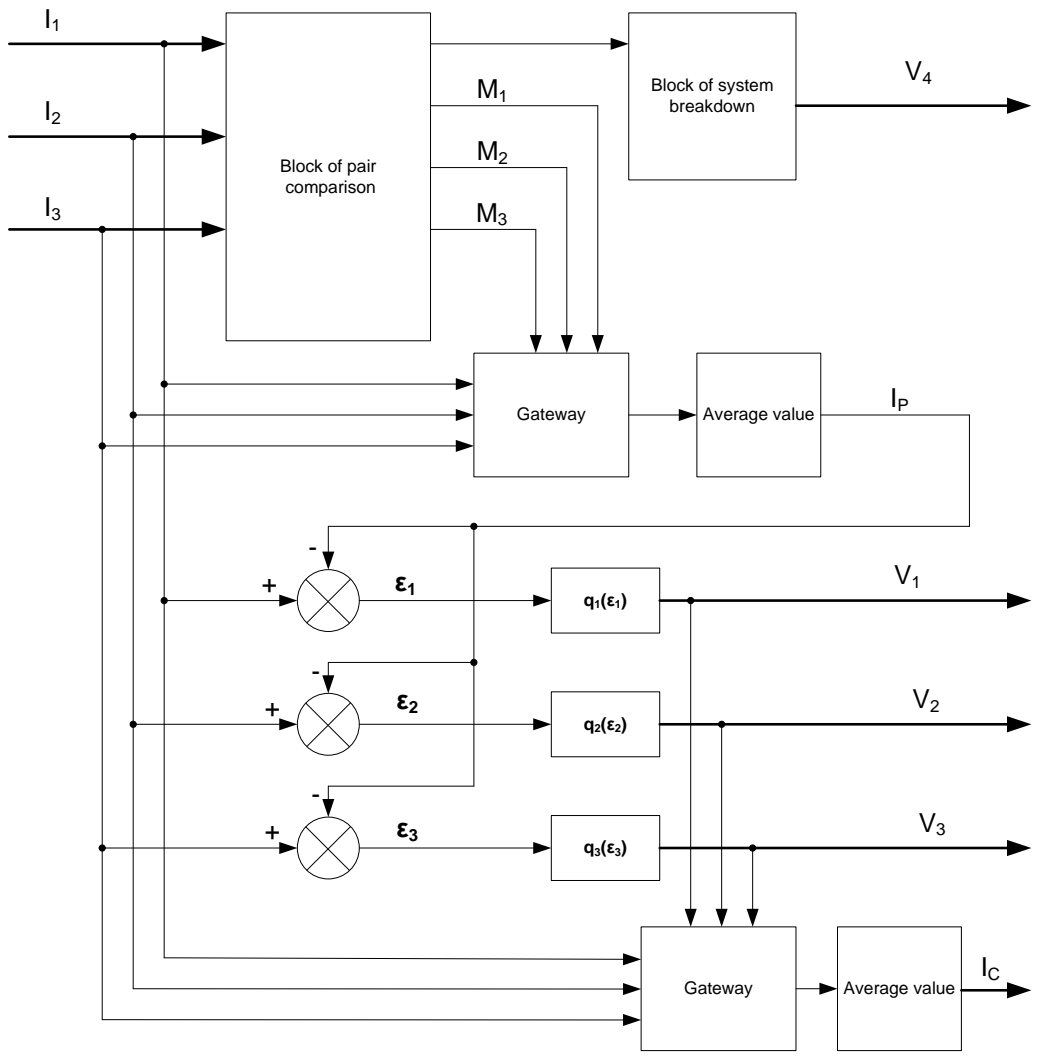

Figure 6

The scheme of the diagnostic/backup system for engine speed measurement

The operation of the diagnostic/backup module can be described as follows:

- The input of the system consists of three parameters representing the speed of engine's compressor $n$ ( $I_{1^{-}}$optical sensor, $I_{2^{-}}$successive integration model, $I_{3^{-}}$ neural network). These signals are transferred through a block of pair comparison, where the maximal errors between the compared pair are defined in Table 1. The allowed error is computed as the sum of the allowed errors for each pair. The optical sensor operates with a maximal error of $200 \mathrm{rpm}$. The models have defined errors as the maximal absolute error compared to real world testing data. The successive integration model has the tolerated error of $2510 \mathrm{rpm}$ and a neural network has the maximal absolute error of $696 \mathrm{rpm}$. 
Table 1

Pair comparison of individual inputs

\begin{tabular}{|c|c|}
\hline $\begin{array}{c}\text { Pair comparison of } \\
\boldsymbol{i} \text {-th } \text { and } \boldsymbol{j} \text {-th } \text { input: }\end{array}$ & $\begin{array}{l}\text { Allowed error margin } \\
\left.\boldsymbol{\varepsilon}_{\mathbf{j}, \mathbf{p o v}}\right)[\mathbf{r p m}]:\end{array}$ \\
\hline $\mathrm{I}_{1}$ and $\mathrm{I}_{2}$ & 2710 \\
\hline $\mathrm{I}_{1}$ and $\mathrm{I}_{3}$ & 896 \\
\hline $\mathrm{I}_{2}$ and $\mathrm{I}_{3}$ & 3006 \\
\hline
\end{tabular}

- After pair comparison, the inputs in the defined tolerances are set and gating elements values $M_{1}, M_{2}$ and $M_{3}$ are set. These values $\{0,1\}$ directly influence the inputs into the average value $I_{P}$.

- If all the gates are set to the value of 0 , the activation of the block - "Total Failure" is executed. The action element is then put into failsafe position and total failure is also signalized.

- $\quad I_{P}$ at last enters substraction elements where the error residuum $\varepsilon_{i}$ is generated and transferred through the function of $q_{i}$. This function sets if the given input is without error or not. State is represented by signalization $V_{i}$. The allowed residuum are set as follows:

- optical sensor

$$
q_{1}=\left\{\begin{array}{l}
1, \text { for }: \varepsilon_{i} \leq|2000| \\
0, \text { for }: \varepsilon_{i}>|2000|
\end{array}\right\}
$$

- $\quad$ artificial neural network

$$
q_{2}=\left\{\begin{array}{l}
1, \text { for }: \varepsilon_{i} \leq|1500| \\
0, \text { for }: \varepsilon_{i}>|1500|
\end{array}\right\}
$$

- $\quad$ successive integration model

$$
q_{3}=\left\{\begin{array}{l}
1, \text { for }: \varepsilon_{i} \leq|800| \\
0, \text { for }: \varepsilon_{i}>|800|
\end{array}\right\}
$$

- The values $V_{i}$ gate the input signals $I_{i}$ and the arithmetic value $I_{C}$ is then computed and enters the control circuit. 


\section{Practical Evaluation of the Proposed Model}

The proposed and implemented diagnostic/backup system has been experimentally tested on an MPM-20 engine within its operational speed range. This means that all tests presented in the following figures contain real-world measured data where the diagnostic system is operating in real time and uses data obtained from the data acquisition system. The data acquisition system consists of sensors, National Instruments data acquisition hardware (cDAQ 9172, NI 9263, NI 9205, NI 9472, NI 9423, NI 9213) and National Instruments LabView software used for data acquisition. The system runs at a sampling rate of $100 \mathrm{~Hz}$ for analogue channels, at $10 \mathrm{~Hz}$ for speed measurements and at $100 \mathrm{~Hz}$ for computations. Everything is down sampled to the rate of $10 \mathrm{~Hz}$ in result, which is sufficient for a turbojet engine with the time constant of 2 seconds [10, 11].

The faultless operation of the system is shown on the graph presented in Figure 7. The engine was run for 70 seconds and the graph shows the course of its speed obtained by different means (optical sensor, polynomial model, neural network) during accelerations and decelerations and the output from the diagnostic/backup system. During the following experiments, failures of sensors were simulated as we cannot physically damage a sensor or computational model (control system input in general) so a special algorithm in LabView was prepared that triggered preprogrammed sensor failures by adding a preset value to its output or completely zeroing its output, thus generating an error signal.

The following real-world tests were executed:

- simulation of the random added values of individual inputs,

- simulation of failures of individual inputs,

- total failure of the sensors.

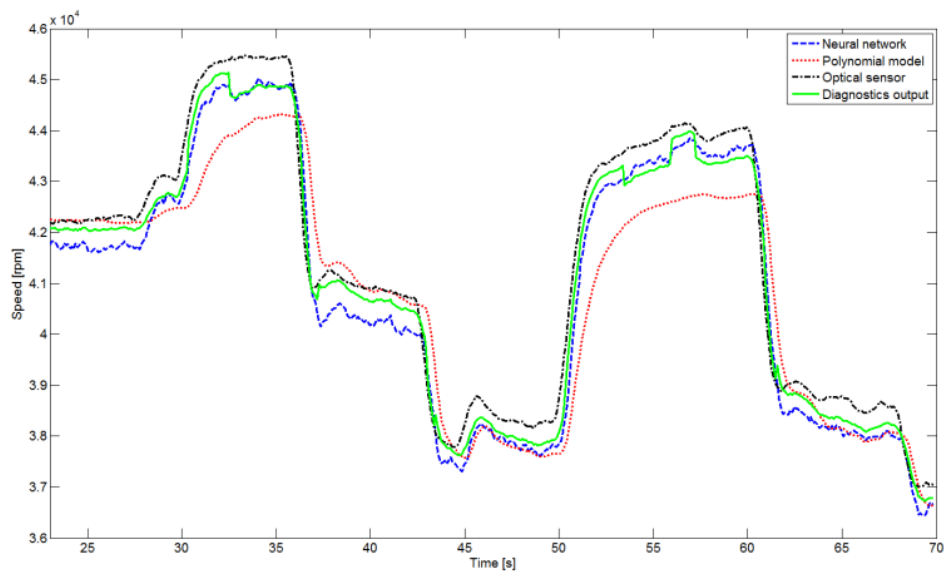

Figure 7

Outputs during faultless operation 


\section{Testing with Generated Random Faults}

Individual outputs were burdened by added speed of $15000 \mathrm{rpm}$. The response of the system can be seen in Figure 8. The output in the graph shows that the generated errors of individual outputs did not translate into the final output of the diagnostic system. The figure also shows that some real failures occurred on the optical sensor (at 30 and 45 seconds). This test demonstrates that the proposed diagnostic/backup system can handle such failures and won't translate them further into the control system where the speed of the engine is used.

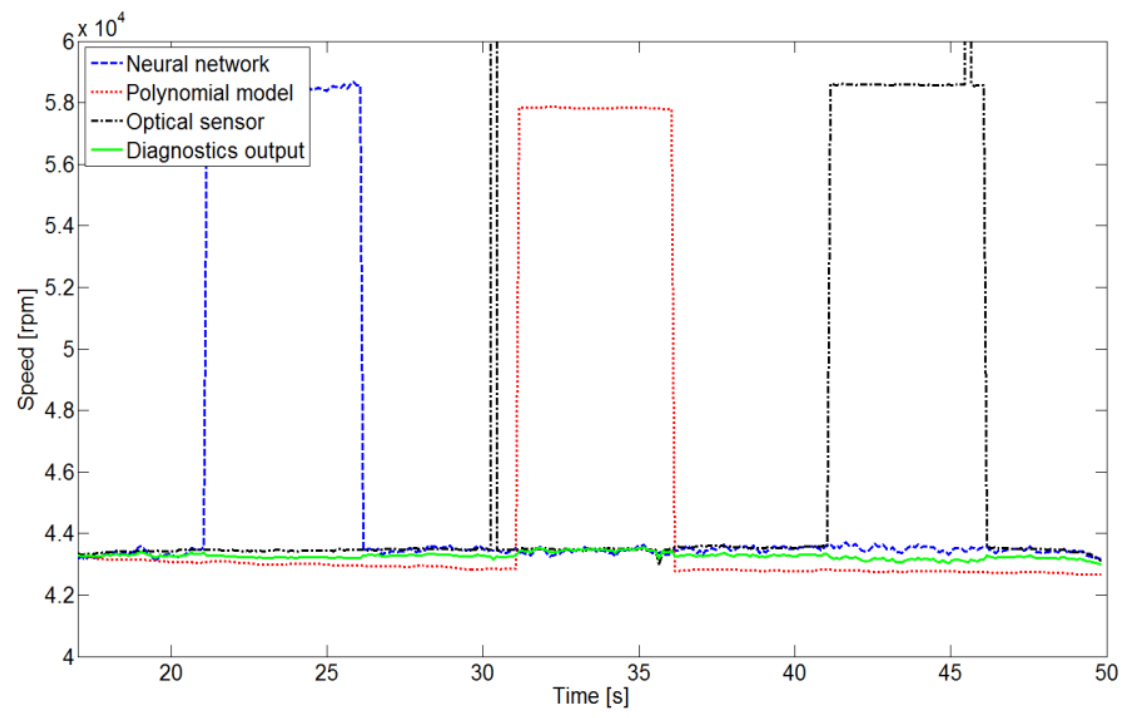

Figure 8

Measured data with applied random errors

\section{Simulation of Failures of the Outputs}

In this case during operation of the engine, failures of individual outputs were generated by setting them to zero. The resulting output is shown in Figure 9. The test again shows that output of the diagnostic/back-up module is not influenced by any of the failures. The green line represents the signal, which is sent into the control system and is not influenced by any of the failures. 


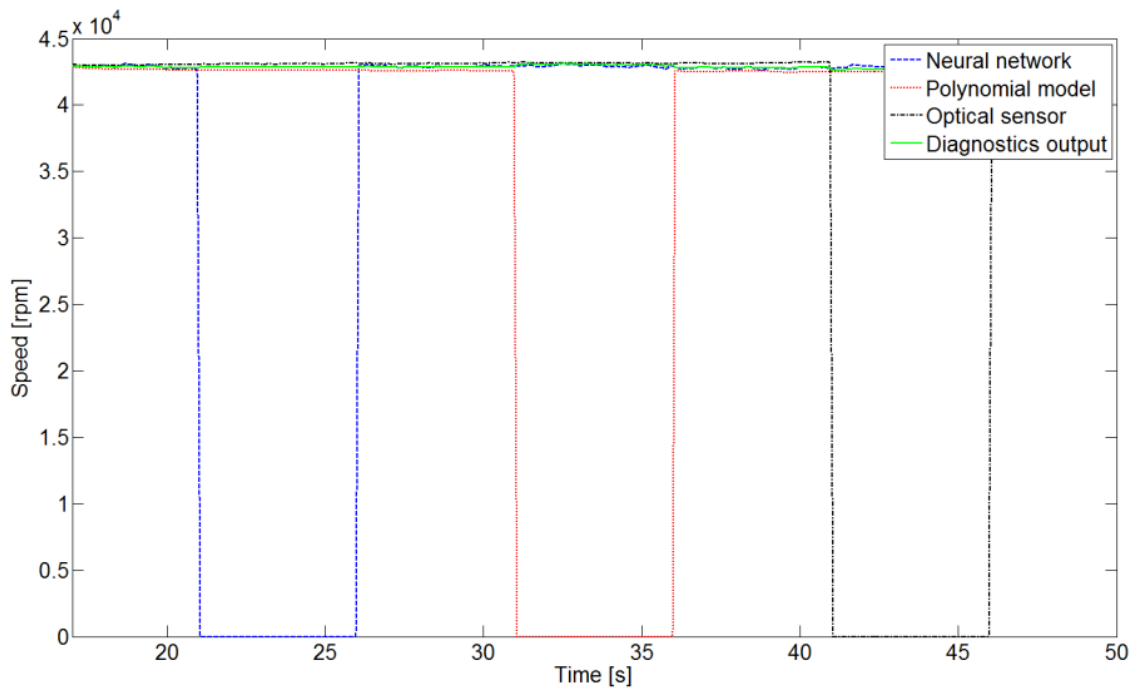

Figure 9

Measured data with failures of individual inputs

\section{Total System Failure}

The last experimentally evaluated part was the testing of the total failure mode. In this case, the model value of the neural network was increased by $25000 \mathrm{rpm}$ and the value of $15000 \mathrm{rpm}$ was added to the successive iteration model (Fig. 10).

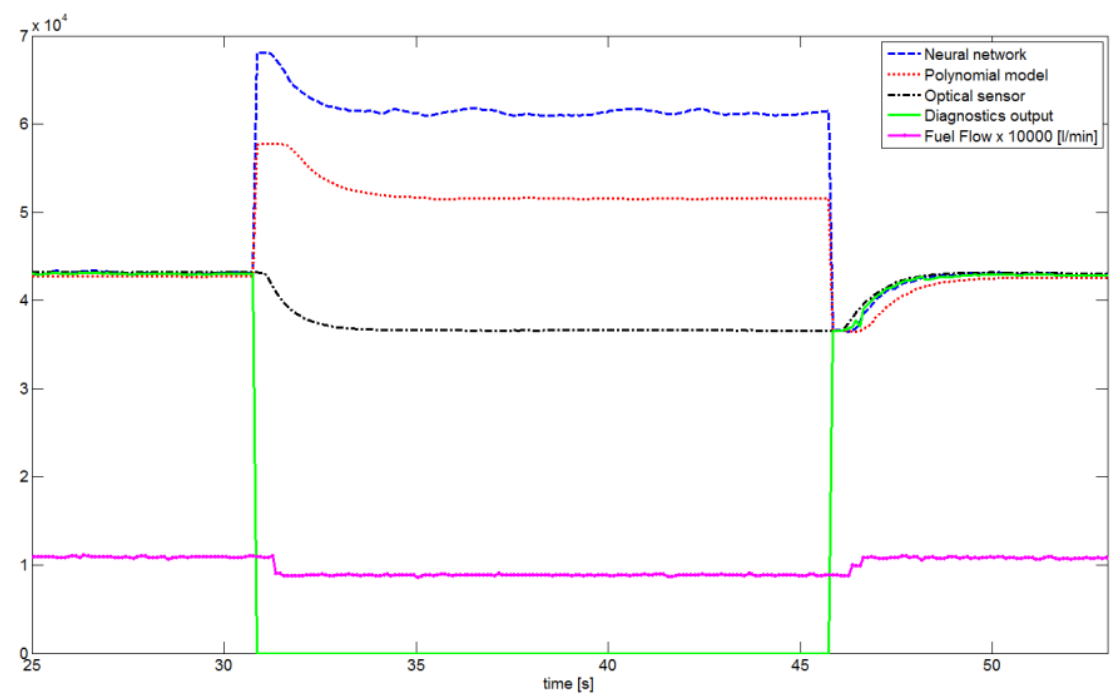

Figure 10

Response of the system to total failure with degraded control mode 
Under such conditions, the voting method cannot decide which of the outputs is relevant, because every one of them exceeds the maximal value for pair comparison. The output of the diagnostic module is then set to zero with a signal of total failure mode in the graphic user interface and the activation of a failsafe regime of control. In the failsafe regime of control, the fuel flow supply into the engine is preset to $0.9 \mathrm{l} / \mathrm{min}$. this is shown in the figure 10. If the errors are gone, the fuel flow supply is set back into normal operational mode and the control system transitions into normal control laws for the stable operating regime.

The occurrence of random failures was precisely simulated in the LabView environment, and it is possible to compare the outputs of the diagnostic/backup system with true sensor value of the speed.

During the test with random errors, the diagnostic system operated with a mean average error of $\mathrm{MAE}=210.116 \mathrm{rpm}$ and maximal absolute average error MAAE $=539.40 \mathrm{rpm}$. The representative graphical depiction of these courses is shown in Fig. 11.

In the experiment with individual input failures the errors were as follows MAE= $241.756 \mathrm{rpm}$ a MAAE $=577.2548 \mathrm{rpm}$. The course of the error is shown in Fig. 11.
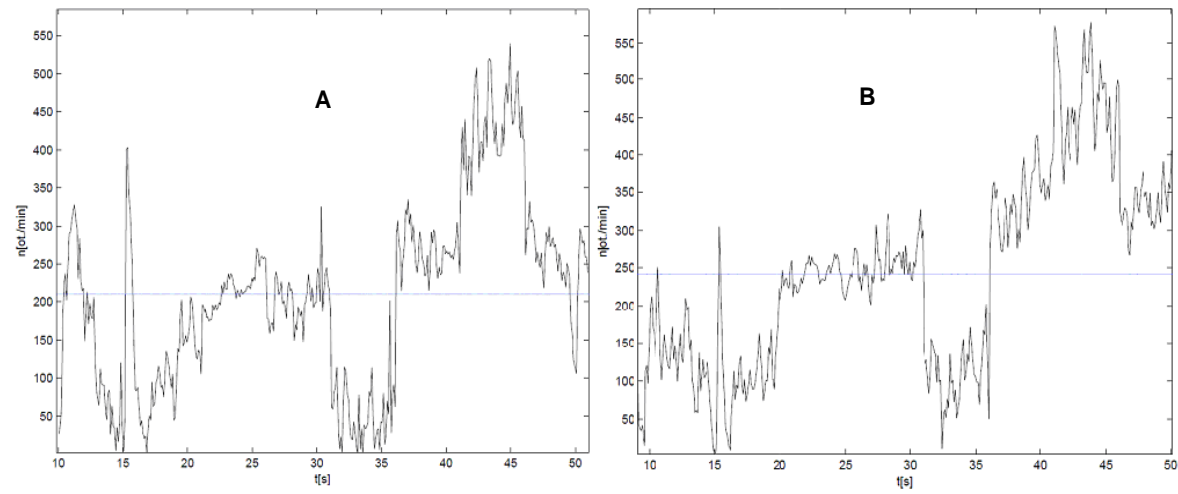

Figure 11

Difference of values from optical sensor and diagnostic system in the experiment with random values

(A) and the experiment with input failures (B)

The presented figures show that the highest error occurred with the failure of the optical sensor (time between 42 and 47 seconds), as it operates with the highest precision and was taken as the reference in the creation of models. However, this error is on the level of $500-600 \mathrm{rpm}$ (5\% of the operating range) and is acceptable for the diagnostic system.

The real-world tests show that the designed and realized diagnostic/backup system operates correctly according to demands put on it. The method is relatively simple for implementation and its main advantage is combination of backup and diagnostic properties in a single unit contrary to other approaches in the field of turbojet engines $[6,7,13]$. 


\section{Conclusions}

The presented diagnostic/backup system utilizes the voting majority method, which is, however, expanded with the methodology of quorum and model based parameter evaluation. The main advantage of such a system is that it combines diagnostics and at the same time operates as a backup system as it uses all available data to synthesize output value. Applying neural networks and successive iteration computational models into the system allows us to increase redundancy of the system without adding any back-up sensor. This redundancy can be increased further by utilizing other measured inputs. The system is designed in a modular way and can be implemented to distributed computational architectures so each module can run on different hardware if needed. The other advantage is its incorporation into situational control systems, which allow controlling the engine under all situations including atypical ones.

\section{Acknowledgement}

The work presented in this paper was supported by VEGA, Grant Agency of Ministry of Education and Academy of Science of Slovak Republic under Grant No. 1/0298/12 - "Digital control of complex systems with two degrees of freedom" and grant No. 1/1117/11 - "Integration of automatic flight control algorithms with control algorithms of aircraft turbocompressor engines". The work presented in this paper was also supported by KEGA under Grant No. 018TUKE4/2012 - "Progressive methods of education in the area of control and modeling of complex systems object oriented on aircraft turbo-compressor engines.

\section{References}

[1] KELEMEN, M., LAZAR, T., KLECUN, R.: Ergatické systémy a a bezpečnost' v letectve (Ergatic systems and aviation safety). AOS gen. M.R. Štefánika, Liptovský Mikuláš, 2009, 316 pp, ISBN 978-80-8040-3836

[2] LINKE-DIESINGER, Andreas: Systems od Commercial Turbofan Engines: An Introducion to Systems Functions. Hamburg, 2008. 239 pp. ISBN 078-3-540-73619-6

[3] ROLLS-ROYCE: The Jet Engine, Fifth edition, Great Britain 1996, 292 pp., ISBN 0902121235

[4] BOYCE P. MEHERWAN: Gas Turbine Engineering Handbook, Third Edition, Elsevier 2006, 935 pp., ISBN 0-88415-732-6

[5] WEIZHONG, Y., LI., C., J., GOEBEL, K.., F.: Multiple Classifier System for Aircraft Engine Fault Diagnosis, Proceedings of the $60^{\text {th }}$ Meeting of the Society For Machinery Failure Prevention Technology MFPT), pp. 291300, 6167, pp. 271-279, 2006 
[6] ARMSTRONG J. B., SIMON D. L.: Implementation of an Integrated OnBoard Aircraft Diagnostic System, NASA/TM-2012-217279, AIAA2011-5859, 2012

[7] JAW C. Link, MATTINGLY D. Jack: Aircraft Engine Controls Design, System Analysis, And Health Monitoring, American Institute of Aeronautics and Astronautics, 2009, pp. 361, ISBN 978-1-60086-705-7

[8] KULIKOV Gennady G., THOMPSON A. Thompson: Dynamic Modelling of Gas Turbines Identification, Simulation, Condition Monitoring and Optimal Control, Springer 2004, 337 pp., ISBN 1852337842

[9] LAZAR, Tobiáš - MADARÁSZ, Ladislav (Eds.): Inovatívne výstupy z transformovaného experimentálneho pracoviska $\mathrm{s}$ malým prúdovým motorom (Inovative Outputs from the Transformed Experimental Laboratory with a Small Turbojet Engine). elfa, s.r.o. Košice, 348 pp. ISBN 978-80-8086-170-4 (2011)

[10] MADARÁSZ, Ladislav et al.: Situational Control Modeling and Diagnostics of Large Scale Systems. In: Towards Intelligent Engineering and Information Technology. Studies in Computational Intelligence 243. ISBN 978-3-642-03736-8, ISSN 1860-969X, 2009, Springer - Verlag Berlin Heidelbeg, pp. 153-164

[11] MADARÁSZ, Ladislav - ANDOGA, Rudolf - FÖZÖ, Ladislav: Intelligent Technologies in Modeling and Control of Turbojet Engines. In: New Trends in Technologies: Control, Management, Computational Intelligence and Network Systems, Meng Joo Er (Ed.), Sciyo, Available on: http://www.intechopen.com/articles/show/title/intelligent-technologies-inmodeling-and-control-of-turbojet-engines,. pp. 17-38, ISBN: 978-953-307213-5, (2010)

[12] ANDOGA, Rudolf - MADARÁSZ, Ladislav - KAROL, Tomáš - FÖZÖ, Ladislav - GAŠPAR, Vladimír: Intelligent Supervisory System for small Turbo-jet. In: Aspects of Computational Intelligence: Theory and Applications (2012). Springer Verlag Berlin Heidelberg, 2012, pp. 85-104, ISBN 978-3-642-30667-9, ISSN 2193-9411

[13] KYRIAZIS A., MATHIOUDAKIS K.: Gas Turbine Fault Diagnosis Using Fuzzy-based Decision Fusion, JOURNAL OF PROPULSION AND POWER Vol. 25, No. 2, March-April 2009, ISSN 0748-4658

[14] PEČINKA, Jiř́; JÍLEK, Adolf: Preliminary Design of a low-cost Mobile Test Cell for Small Gas Turbine Engines (GT2012-69419) In: Proceedings of ASME Turbo Expo 2012. Copenhagen: ASME, 2012

[15] Yi-Jen Mon, Chih-Min Lin, Imre J. Rudas: Wireless Sensor Network (WSN) Control for Indoor Temperature Monitoring, Acta Polytechnica Hungarica Vol. 9, No. 7, ISSN 1785-8860, 2012 